\title{
Falls Among the Elderly in Peruvian Andean Communities and the Rural far South of Brazil: Prevalence and Associated Factors
}

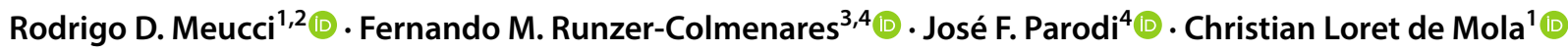

๑) Springer Science+Business Media, LLC, part of Springer Nature 2019

\begin{abstract}
Falls are the fifth leading cause of death and are one of the main causes of hospitalization. The literature about falls prevalence among older adults living in rural/remote communities in South America is scarce. To compare falls prevalence among the elderly in the Andes, Peru, and in the rural area of the municipality of Rio Grande, Rio Grande do Sul state, Brazil. Two separate cross-sectional studies were conducted in Peru, Andes $(\mathrm{N}=413)$, and Brazil, Rio Grande, Rio Grande do Sul state $(\mathrm{N}=1029)$. We stratified all data analysis according to location (Andes/Rio Grande). Characteristics of the samples were compared and the chi square test for proportions was used. Falls prevalence was then calculated for each independent variable and crude and adjusted prevalence ratios were estimated using Poisson Regression with robust variance. Falls prevalence in the last year was much higher in the Andes (64.1\%) than in Rio Grande (25.3\%). For most characteristics assessed, falls prevalence in Peru was at least double that found in Rio Grande. According to the adjusted analysis for the Andes, age (80 or more), being married, divorced and alcohol intake were significantly associated with falls. In Rio Grande, female gender and being in the 70-79 and 80 or more age ranges were associated with falls as well as those who self-rated their health as poor. This paper contributes to knowledge about falls prevalence among the elderly from rural and remote communities in two South American countries. Longitudinal multicentre studies with standardized methodologies are recommended.
\end{abstract}

Keywords Elderly $\cdot$ Prevalence $\cdot$ Falls $\cdot$ Rural areas

\section{Introduction}

Ageing is a global process which has been taking place more quickly in developing countries in South America such as Brazil and Peru [1,2]. This phenomenon challenges health

Rodrigo D. Meucci

rodrigodalke@gmail.com

1 Postgraduate Program in Public Health, Federal University of Rio Grande (FURG), Rua General Osório, 102. $3^{\circ}$ andar. Centro, Rio Grande, RS, Brazil

2 Postgraduate Program in Health Sciences, School of Medicine, Federal University of Rio Grande (FURG), Rua General Osório, 102. $3^{\circ}$ andar. Centro, Rio Grande, RS, Brazil

3 Facultad de Ciencias de la Salud, Carrera de Medicina Humana, Universidad Científica del Sur, Panamericana Sur Km 19, Villa, Lima, Peru

4 Facultad de Medicina Humana, Centro de Investigación del Envejecimiento (CIEN), Universidad de San Martín de Porres, Alameda del Corregidor 1531, Urb. Los Sirius, Las Viñas, La Molina, Lima, Peru systems, since expenditure on injuries and chronic health conditions related to aging increases each year.

Falls are the fifth leading cause of death and are one of the main causes of hospitalization and complications among the elderly [3]. A fall is defined as "inadvertently coming to rest on the ground, floor or other lower level, excluding intentional change in position to rest on furniture, against walls or other objects" [4]. Falls are a result of a combination of extrinsic (environmental) and intrinsic (poor postural control due to organic abnormalities) factors [5]. According to the World Health Organization, approximately $30 \%$ of aged people fall each year [4]. In Latin America and the Caribbean, falls prevalence in urban metropolises ranges from $21.6 \%$ in Barbados (Bridgetown) to $34.0 \%$ in Chile (Santiago) [6]. In Brazil, a nationwide study with a sample of urban elderly reported fall prevalence of $27.6 \%$, which was associated with female gender, older age, low socioeconomic status, obesity and sedentary lifestyles [7].

Although the elderly from isolated communities usually have poorer health than their urban counterparts [8], the literature about falls prevalence and its consequences 
among older adults living in rural/remote communities in South America is scarce. Only one recent study on a rural community in Ecuador reported a falls prevalence of 53\% [9]. Moreover, most studies about falls in rural/remote populations are from Australia [8] and Asia [10].

Due to the lack of knowledge about falls prevalence in rural populations in South American countries, the objective of this paper is to compare falls prevalence among the elderly in the Andes, Peru, and in the rural area of the municipality of Rio Grande, Rio Grande do Sul state, Brazil, as well as to examine associated factors.

\section{Methods}

Two separate cross-sectional studies were conducted in Peru, Andes, and Brazil, Rio Grande, Rio Grande do Sul state and the methodologies are described below.

\section{Andes}

Data on Peruvian Andean elderly was collected for a cross-sectional study, carried out with inhabitants from eleven high-altitude communities: La Jalca, Leimebamba, Llupa, San Pedro de Chaná, Atipayán, Pampamarca, Chacapampa, Ayahuanco, Paucarcolla, Vilca and Viñac, between 2013 and 2017. Participants were all of the same ethnic group (indigenous and mestizos) with farming, trading and agriculture as their main work activities. All communities were located at $1500 \mathrm{~m}$ or more above sea level, with diverse weather conditions: rainfall, high temperatures, cloudy, depending on the region. In the original data collection study, researchers performed a non-probabilistic, census-type sampling procedure and registered approximately $95 \%$ of all the elderly inhabitants of each community; the sample included 413 older adults who voluntarily signed an informed consent form to be part of the study [11]. When applicable, legal guardians signed the informed consent form.

Participants were visited at home one to three times to be enrolled in the study. Data was collected about sociodemographic characteristics, medical background, disability, physical performance, anthropometric measurements, social and mental health [12]. Information about gender, age and marital status was obtained from their national identification documents. We asked for self-reported information-confirmed by family or caregivers-about education, smoking, alcohol consumption during the last 12 months and comorbidities. Participants' height and weight data was used to calculate their body mass index. Finally, researchers asked the participants about falls in the last 12 months [13].

\section{Rio Grande}

Rio Grande is a municipality in the south of Rio Grande do Sul state, Brazil, located between "Lagoa dos Patos" and the Atlantic Ocean, covering an area of $2708.4 \mathrm{~km}^{2}$. It is a port city and is one of the largest ports in Brazil, serving as an export corridor for commodities such as soybean and rice [14]. In 2017, its population was estimated as being 209,378 inhabitants, almost $95 \%$ of whom lived in urban areas [15]. Its rural population is dispersed over a vast territory and includes traditional communities such as those from "Ilha dos Marinheiros" and "Ilha da Torotama", who live mainly from fishing and family farming.

According to the Brazilian Institute of Geography and Statistics [15], the rural area of the municipality consists of 24 census tracts with approximately 8500 inhabitants distributed between 2700 permanently inhabited households. A systematic random sampling process was used in order to select $80 \%$ of the households. A number between "1" and "5" was drawn, whereby the drawn number corresponded to the household that was skipped. For example, if number "3" was drawn, every household numbered as " 3 " in a sequence of five households was not sampled, i.e. it was skipped. This procedure ensured that four out of five households were sampled. All residents aged $\geq 60$ in the selected households were eligible. Institutionalized individuals were excluded [16], and the final sample included 1029 older adults.

Data collection took place from April to October 2017 and was conducted by a team of trained interviewers and supervisors. Once the team arrived at a selected household, eligible individuals were invited to participate in the study. After acceptance, the elderly person signed an Informed Consent Form (ICF). The questionnaire was then administered. Caregivers or legal guardians signed the ICF for the elderly with disabilities.

The data collection instrument used was an electronic questionnaire [17] which investigated sociodemographic characteristics such as sex, age, years of schooling, marital status, working status, smoking (never, former smoker, current smoker), alcohol intake in the last 7 days, selfrated health (very good, good, regular, bad, very bad), medical diagnosis of hypertension, diabetes, lung disease and self-reported height and weight.

The outcome, namely falls in the last 12 months, was asked about by means of the question "Have you fallen in the last 12 months?" If the answer was "yes", the respondent was then asked, "How many times have you fallen?"

The Rio Grande study was approved by the Ethics Research Committee of the Federal University of Rio Grande, under Opinion no. 51/2017, case $23116.009484 / 2016-26$, with the confidentiality of the individual information of the participants being assured. 


\section{Data Analysis}

Andes and Rio Grande datasets were appended using Stata 13. Schooling was categorized in years of schooling: no education (0 year), elementary (1-8 years of schooling), high school (9-11 years of schooling), university/technical school ( $\geq 11$ years).

Smoking was dichotomized as non-smokers (never smoked/former smokers) and current smokers. Self-rated health was categorized as bad, regular, good and very good, while body mass index was categorized as low weight $\left(<18.5 \mathrm{~kg} / \mathrm{m}^{2}\right)$, normal weight ( 18.5 to $\left.24.99 \mathrm{~kg} / \mathrm{m}^{2}\right)$, overweight $\left(25.0\right.$ to $\left.29.9 \mathrm{~kg} / \mathrm{m}^{2}\right)$ and obesity $\left(\geq 30.0 \mathrm{~kg} / \mathrm{m}^{2}\right)$.

We stratified all data analysis according to location (Andes/Rio Grande). Characteristics of the samples were compared and the chi square test for proportions was used. Falls prevalence was then calculated for each independent variable and crude and adjusted prevalence ratios were estimated using Poisson Regression with robust variance. The Wald test for heterogeneity or linear trend was used for polytomic or ordinal exposures, respectively.

Adjusted analysis was performed according to a hierarchical model with four levels. The first level included sex, age, schooling (dichotomic), marital status and work; the second, smoking and alcohol intake; third, hypertension, lung disease, diabetes and BMI; the fourth, self-rated health. Variables with a p-value below 0.20 were kept in the model, and those with a p-value $<0.005$ were considered to be associated with the outcome.

\section{Results}

All characteristics, except smoking, were different between the elderly from the Andes and Rio Grande. In the Andes, women $(65.6 \%)$, the $60-69$ age group $(47.8 \%)$, illiterate $(82.3 \%)$ and married individuals $(58.1 \%)$ were predominant. Most Andeans were still working (52.1\%), self-rated their health as very good (83.3\%) and were in the low/normal weight group (46.1\%). In Rio Grande the elderly population was mostly male (55.2\%), was $60-69$ years old (51.4\%), had one to eight years of schooling $(71,7 \%)$, self-rated their health as good (47.4\%), and $22.5 \%$ were obese. Hypertension, lung diseases and diabetes were more common in Rio Grande (Table 1).

Falls prevalence in the last year was much higher in the Andes (64.1\%) than in Rio Grande (25.3\%). Crude analysis shows that age ( 80 or more) and marital status were associated with the outcome in both locations. Smoking was associated in the Andes, while sex (female) and self-rated health were only associated in Rio Grande (Table 2).

For most characteristics assessed, falls prevalence in Peru was at least double that found in Rio Grande, except for
Table 1 Characteristics of the elderly in the Andes (Peru) and Rio Grande (Rio Grande do Sul state, Brazil)

\begin{tabular}{|c|c|c|c|c|c|}
\hline & \multicolumn{2}{|c|}{ Andes } & \multicolumn{2}{|c|}{ Rio Grande } & \multirow[t]{2}{*}{$\mathrm{P}$} \\
\hline & $\mathrm{N}$ & $\%$ & $\mathrm{~N}$ & $\%$ & \\
\hline Sex & & & & & $<0.001$ \\
\hline Female & 272 & 65.9 & 461 & 44.8 & \\
\hline Male & 141 & 34.1 & 568 & 55.2 & \\
\hline Age (years) & & & & & $<0.001$ \\
\hline $60-69$ & 138 & 33.6 & 528 & 51.4 & \\
\hline $70-79$ & 196 & 47.7 & 327 & 31.8 & \\
\hline 80 or more & 77 & 18.7 & 173 & 16.8 & \\
\hline Schooling (years) & & & & & $<0.001$ \\
\hline 0 & 340 & 82.3 & 206 & 20.3 & \\
\hline $1-8$ & 71 & 17.2 & 729 & 71.7 & \\
\hline 9 or more & 2 & 0.5 & 14 & 1.4 & \\
\hline University/Tech School & 0 & 0.0 & 67 & 6.6 & \\
\hline Marital status & & & & & $<0.001$ \\
\hline Single & 44 & 10.6 & 95 & 9.2 & \\
\hline Married & 240 & 58.1 & 639 & 62.1 & \\
\hline Divorced & 11 & 2.7 & 83 & 8.1 & \\
\hline Widowed & 118 & 28.6 & 212 & 20.6 & \\
\hline Working & & & & & $<0.001$ \\
\hline No & 198 & 47.9 & 875 & 85.0 & \\
\hline Yes & 215 & 52.1 & 154 & 15.0 & \\
\hline Smoking & & & & & 0.5 \\
\hline No & 364 & 88.1 & 892 & 86.8 & \\
\hline Yes & 49 & 11.9 & 136 & 13.2 & \\
\hline Alcohol intake ${ }^{a}$ & & & & & $<0.001$ \\
\hline No & 294 & 71.2 & 857 & 83.3 & \\
\hline Yes & 119 & 28.8 & 172 & 16.7 & \\
\hline \multicolumn{6}{|l|}{ Hypertension } \\
\hline No & 369 & 89.4 & 464 & 45.1 & \\
\hline Yes & 44 & 10.6 & 564 & 54.9 & \\
\hline Lung disease & & & & & 0.03 \\
\hline No & 397 & 96.1 & 957 & 93.2 & \\
\hline Yes & 16 & 3.9 & 70 & 6.8 & \\
\hline Diabetes & & & & & $<0.001$ \\
\hline No & 382 & 92.5 & 866 & 84.3 & \\
\hline Yes & 31 & 7.5 & 161 & 15.7 & \\
\hline BMI & & & & & $<0.01$ \\
\hline Low/normal weight & 167 & 46.1 & 370 & 37.6 & \\
\hline Overweight & 134 & 37.0 & 392 & 39.9 & \\
\hline Obesity & 31 & 16.9 & 221 & 22.5 & \\
\hline \multicolumn{6}{|l|}{ Self-rated health } \\
\hline Poor & 14 & 3.4 & 78 & 7.6 & \\
\hline Regular & 22 & 5.3 & 357 & 34.8 & \\
\hline Good & 33 & 8.0 & 486 & 47.4 & \\
\hline Very good & 344 & 83.3 & 104 & 10.2 & \\
\hline Falls & & & & & $<0.001$ \\
\hline No & 148 & 35.9 & 766 & 74.7 & \\
\hline Yes & 264 & 64.1 & 259 & 25.3 & \\
\hline
\end{tabular}


Table 1 (continued)

${ }^{\mathrm{a}}$ Alcohol intake: during the last 12 months in the Andes; in the last 07 days in Rio Grande

those with lung disease prevalence ratio (PR) 1.90 (95\% confidence interval (CI) 1.14-3.16), diabetes PR 1.91 (95\% CI 1.30-2.79), and poor self-rated health PR 1.62 (95\% CI 1.00-2.61) (Table 2).

According to the adjusted analysis, in the Andes, age (80 or more) PR 1.27 (95\% CI 1.05-1.53), being married PR 1.40 (95\% CI 1.01-1.94) and divorced PR 1.92 (95\% CI 1.30-2.84), alcohol intake PR 1.33 (95\% CI 1.16-1.52) were significantly associated with falls. Obesity prevented falls by 23\% PR 0.77 (95\% CI 0.60-0.97). In Rio Grande, women PR 1.45 (95\% CI 1.18-1.79) and the 70-79 and 80 or more age ranges were associated with falls. Those who rated their health as poor were at higher risk of reporting falls PR1.86 (95\% CI 1.14-3.03) (Table 3).

\section{Discussion}

We found that falls prevalence among the elderly in the Andes was almost three times higher than in Rio Grande, and age was the common associated factor in both localities. Female sex and self-rated health were only associated in Rio Grande, while marital status, BMI and alcohol consumption were only associated in the Andes.

The Andeans were older and had a higher proportion of females than their Rio Grande counterparts. These demographic characteristics may partly explain falls prevalence disparities as the literature consistently shows that the older elderly and females are at higher risk of falling than their counterparts. Despite demographic differences, a recent study from Ecuador with elderly people from a rural community reported fall prevalence of $53 \%$. The authors attributed this finding to the unevenness of village's unpaved streets [9]. In the Peruvian Andes, streets in the highlands have similar conditions, being stony, narrow, steeply sloping and slippery. Also, in the Andes, very narrow and uneven trails are used in farming activities.

The prevalence rate found in the rural area of the municipality of Rio Grande is similar to that reported in urban Brazilian localities [7]. Although the streets in the rural area of Rio Grande are also not paved, the ground is flat, which does not predispose individuals to falling as it does in the Andes. However, it is important to note that in both places, household characteristics, such as front step, rugs and lighting were not measured. Regardless of unmeasured variables, falls prevention and management strategies need to be implemented to optimize intrinsic elderly capacities, especially in the Andes. Adequate service responses and correction of architectural barriers can optimize functional capacity of older adults on the way to achieving healthy ageing [18].

Age was the only common associated factor in both localities, which is consistent with the literature [3]. Decline of physical, cognitive and affective capacities as well as comorbidities and frailty leave individuals more prone to falls [4].

Being divorced is associated with the outcome in the Andes and may be a consequence of poorer living and working conditions. In fact, the literature tends to identify widowed status as being associated with falls, but in the Andes being divorced may result in a situation of vulnerability within the community. Alcohol consumption is a controversial form of exposure to falls and other health-related outcomes [19]. As reported by a study conducted in Arequipa, its plausible that Andean seniors might have frequent binge drinking episodes, especially those who are current drinkers [20]. However, the alcohol drinking pattern was not evaluated either in the Andes or in Rio Grande [21]. The finding that obesity in the Andes prevent falls is in disagreement with the literature [7,22], which usually reports that obesity is a risk factor for falls among the elderly. However, as lean mass was not measured, we cannot reject the hypothesis that in Andes higher BMI means that individuals classified as obese may have better skeletal muscle mass and function, which protects from falls.

In Rio Grande, females have a higher risk of falling than males. Despite some controversial findings in the literature, females usually falls more than males [23]. This could be related to less muscle mass and poor balance among women when compared to men. Also, the negative finding for this association in the Andes may be related to low statistical power due to the sample size in the Andes, as well as high prevalence of the outcome which decreases the magnitude of the effect measured among the Andeans. According to a meta-analysis of longitudinal studies, poor self-rated health is a marker of chronic morbidities and frailty, which are associated with falls [3, 24].

This paper deals with data from studies designed with different objectives and populations. Thus, some exposure variables are not directly comparable, and our findings must be interpreted cautiously. The populations are very different regarding geographic, sociodemographic, behavioral and morbidity characteristics. Also, unmeasured variables such as gait speed, balance, previous falls, sarcopenia and disabilities can play a role in both places. Notwithstanding, all the analyses were stratified, and the paper contributes to knowledge about falls prevalence among elderly people in rural and remote communities in two South American countries. Longitudinal multicentre studies with standardized methodologies are recommended to better understand the reasons for such different prevalence rates found in this study, as well as to explore risk factors in depth. Aging in 
Table 2 Falls among the elderly in the Andes (Peru) and Rio Grande (Rio Grande do Sul state, Brazil) according to independent variables

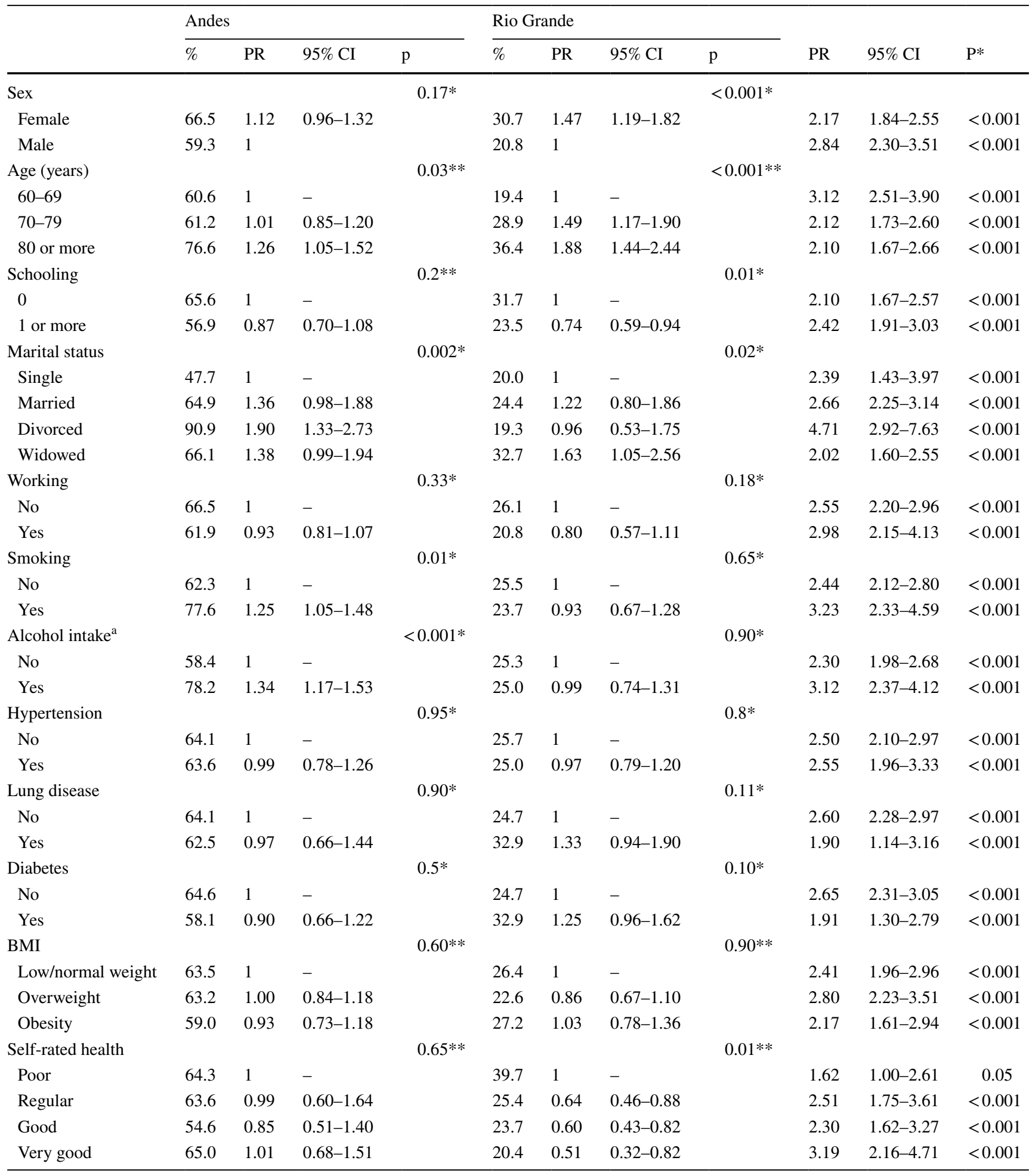

Crude analysis

*Wald test of heterogeneity

**Wald test of linear trend

${ }^{a}$ Alcohol intake: during the last 12 months in the Andes; in the last 07 days in Rio Grande 
Table 3 Falls among the elderly in the Andes (Peru) and Rio Grande (Rio Grande do Sul state, Brazil) according to independent variables

\begin{tabular}{|c|c|c|c|c|c|c|}
\hline & \multicolumn{3}{|c|}{ Andes } & \multicolumn{3}{|c|}{ Rio Grande } \\
\hline & PR & $95 \% \mathrm{CI}$ & $\mathrm{p}$ & PR & $95 \% \mathrm{CI}$ & $\mathrm{p}$ \\
\hline \multicolumn{7}{|l|}{$1^{\circ}$ Level } \\
\hline Sex & & & $0.22 *$ & & & $0.001 *$ \\
\hline Female & 1.11 & $0.94-1.30$ & & 1.45 & $1.18-1.79$ & \\
\hline Male & 1 & & & 1 & & \\
\hline Age (years) & & & $0.03 * *$ & & & $<0.001 * *$ \\
\hline $60-69$ & 1 & - & & 1 & - & \\
\hline $70-79$ & 1.01 & $0.85-1.20$ & & 1.51 & $1.19-1.92$ & \\
\hline 80 or more & 1.27 & $1.05-1.53$ & & 1.69 & $1.29-2.22$ & \\
\hline Schooling & & & 0.18 & & & 0.11 \\
\hline 0 & 1 & - & & 1 & - & \\
\hline 1 or more & 1.16 & $0.93-1.45$ & & 1.21 & $0.95-1.54$ & \\
\hline Marital status & & & $0.01 *$ & & & $0.81^{*}$ \\
\hline Single & 1 & - & & 1 & - & \\
\hline Married & 1.40 & $1.01-1.94$ & & 1.19 & $0.77-1.84$ & \\
\hline Divorced & 1.92 & $1.30-2.84$ & & 1.02 & $0.55-1.87$ & \\
\hline Widowed & 1.38 & $0.98-1.93$ & & 1.19 & $0.74-1.92$ & \\
\hline Working & & & $0.60 *$ & & & $0.95 *$ \\
\hline No & 1 & - & & 1 & - & \\
\hline Yes & 0.96 & $0.83-1.11$ & & 1.01 & $0.72-1.42$ & \\
\hline \multicolumn{7}{|l|}{$2^{\circ}$ Level } \\
\hline Smoking & & & $0.11 *$ & & & $0.34 *$ \\
\hline No & 1 & - & & 1 & - & \\
\hline Yes & 1.16 & $0.97-1.38$ & & 1.17 & $0.85-1.63$ & \\
\hline Alcohol intake & & & $<0.001^{*}$ & & & $0.27 *$ \\
\hline No & 1 & - & & 1 & - & \\
\hline Yes & 1.33 & $1.16-1.52$ & & 1.18 & $0.88-1.58$ & \\
\hline \multicolumn{7}{|l|}{$3^{\circ}$ Level } \\
\hline Hypertension & & & $0.98 *$ & & & $0.14^{*}$ \\
\hline No & 1 & - & & 1 & - & \\
\hline Yes & 1.00 & $0.75-1.32$ & & 0.85 & $0.69-1.06$ & \\
\hline Lung disease & & & $0.70^{*}$ & & & $0.20^{*}$ \\
\hline No & 1 & - & & 1 & - & \\
\hline Yes & 1.08 & $0.76-1.54$ & & 1.26 & $0.89-1.80$ & \\
\hline Diabetes & & & $0.70 *$ & & & $0.05 *$ \\
\hline No & 1 & - & & 1 & - & \\
\hline Yes & 0.93 & $0.68-1.28$ & & 1.30 & $1.00-1.68$ & \\
\hline BMI & & & $<0.04 * *$ & & & $0.97 * *$ \\
\hline Low/normal weight & 1 & - & & 1 & - & \\
\hline Overweight & 0.92 & $0.77-1.10$ & & 0.89 & $0.69-1.14$ & \\
\hline Obesity & 0.77 & $0.60-0.97$ & & 1.04 & $0.77-1.40$ & \\
\hline \multicolumn{7}{|l|}{$4^{\circ}$ Level } \\
\hline Self-rated health & & & $0.80 * *$ & & & $0.03 * *$ \\
\hline Poor & 1.04 & $0.68-1.60$ & & 1.81 & $1.10-2.98$ & \\
\hline Regular & 0.97 & $0.70-1.34$ & & 1.24 & $0.80-1.92$ & \\
\hline Good & 0.83 & $0.60-1.14$ & & 1.20 & $0.79-1.83$ & \\
\hline Very good & 1 & - & & 1 & - & \\
\hline
\end{tabular}

Adjusted analysis

*Wald test of heterogeneity

**Wald test of linear trend

${ }^{a}$ Alcohol intake: during the last 12 months in the Andes; in the last 07 days in Rio Grande 
rural/remote areas of developing countries occurs concomitantly with health budget restrictions [4] and there is an urgent need to find ways to prevent falls in these communities since their consequences (such as disabilities) may be worse than in urban areas due to absence or inadequacy of local health services $[8,25]$.

Funding Rio Grande project received support from the National Council for Scientific and Technological Development (CNPQ) through a research productivity scholarship, as well as from the Coordination for the Improvement of Higher Level Personnel (CAPES)/Ministry of Education and from Pastoral da Criança. Andes study received support from Universidad San Martin de Porres.

\section{Compliance with Ethical Standards}

Conflict of interest The authors declare that they have no conflicts of interest.

\section{References}

1. Olivera, J., \& Tournier, I. (2016). Successful ageing and multidimensional poverty: The case of Peru. Ageing \& Society, 36(8), 1690-1714.

2. Higo, M., \& Khan, H. T. (2015). Global population aging: Unequal distribution of risks in later life between developed and developing countries. Global Social Policy, 15(2), 146-166.

3. Deandrea, S., Lucenteforte, E., Bravi, F., Foschi, R., La Vecchia, C., \& Negri, E. (2010). Risk factors for falls in communitydwelling older people: A systematic review and meta-analysis. Epidemiology (Cambridge, Mass. ), 21(5), 658-668.

4. World Health Organization. (2007). WHO global report on falls prevention in older age. France: World Health Organization.

5. World-Health-Organization. (2017). Integrated care for older people: Guidelines on community-level interventions to manage declines in intrinsic capacity (p. 60). Geneva: World Health Organization.

6. Reyes-Ortiz, C. A., Snih, S. A., \& Markides, K. S. (2005). Falls among elderly persons in Latin America and the Caribbean and among elderly Mexican-Americans. Revista Panamericana de Salud Pública, 17(5-6), 362-369.

7. Siqueira, F. V., Facchini, L. A., Silveira, D. S., Piccini, R.X., Tomasi, E., Thumé, E., et al. (2011). Prevalence of falls in elderly in Brazil: A countrywide analysis. Cadernos de Saúde Pública, 27(9), 1819-1826.

8. Boehm, J., Franklin, R. C., \& King, J. C. (2014). Falls in rural and remote community dwelling older adults: A review of the literature. Australian Journal of Rural Health, 22(4), 146-155.

9. Del-Brutto, O. H., Mera, R. M., Peinado, C. D., \& Sedler, M. J. (2019). Prevalence, severity, and risk of future falls in communitydwelling older adults living in a rural community: The Atahualpa Project. Journal of Community Health, 44(3), 487-497.

10. Romli, M. H., Tan, M. P., Mackenzie, L., Lovarini, M., Suttanon, P., \& Clemson, L. (2017). Falls amongst older people in Southeast Asia: A scoping review. Public Health, 145, 96-112.

11. Estela-Ayamamani, D., Espinoza-Figueroa, J., Columbus-Morales, M., \& Runzer-Colmenares, F. (2013). Physical performance in older adults living at high altitude. Revista Peruana de Medicina Experimental y Salud Pública, 30(2), 358-360.
12. Urrunaga-Pastor, D., Moncada-Mapelli, E., Runzer-Colmenares, F. M., Bailon-Valdez, Z., Samper-Ternent, R., Rodriguez-Mañas, L., et al. (2018). Factors associated with poor balance ability in older adults of nine high-altitude communities. Archives of Gerontology and Geriatrics, 77, 108-114.

13. Urrunaga-Pastor, D., Runzer-Colmenares, F. M., Arones, T. M., Meza-Cordero, R., Taipe-Guizado, S., Guralnik, J. M., et al. (2019). Factors associated with poor physical performance in older adults of 11 Peruvian high Andean communities. F1000Res, $8,59$.

14. Porto-do-Rio-Grande. http://www.portoriogrande.com.br/site/ consultas_estatisticas.php. Rio Grande: Porto do Rio Grande 2019 [cited 2019 03/02]; Retrieved from http://www.portoriogrande. com.br/site/consultas_estatisticas.php.

15. IBGE. (2019). Cadastro Nacional de Endereços para Fins Estatísticos. Brasília: IBGE. Retrieved February 3, 2019, from https:// censo2010.ibge.gov.br/cnefe/.

16. Schroeder, F. M. M., Mendoza-Sassi, R. A., \& Meucci, R. D. Condição de saúde bucal e utilização de serviços odontológicos entre idosos em área rural no sul do Brasil.. Cien Saude Colet Cien Saude Colet [periódico na internet]. 2018;(2018/Dez).

17. Harris, P. A., Taylor, R., Thielke, R., Payne, J., Gonzalez, N., \& Conde, J. G. (2009). Research electronic data capture (REDCap)-A metadata-driven methodology and workflow process for providing translational research informatics support. Journal of Biomedical Informatics, 42, 377-381.

18. World Health Organization. (2015). World report on ageing and health. Luxembourg: World Health Organization.

19. Daskalopoulou, C., Stubbs, B., Kralj, C., Koukounari, A., Prince, M., \& Prina, A. M. (2018). Associations of smoking and alcohol consumption with healthy ageing: A systematic review and metaanalysis of longitudinal studies. British Medical Journal Open, 8(4), $\mathrm{e} 019540$.

20. Medina-LezamaI, J., Morey-VargasI, O. L., Zea-DíazI, H., et al. (2008). Prevalence of lifestyle-related cardiovascular risk factors in Peru: The PREVENCION study. Revista Panamericana de Salud Pública, 24(3), 169-179.

21. Reid, M. C., Boutros, N. N., O’Connor, P. G., Cadariu, A., \& Concato, J. (2002). The health-related effects of alcohol use in older persons: A systematic review. Substance Abuse, 23(3), 149-164.

22. Handrigan, G. A., Maltais, N., Gagné, M., Lamontagne, P., Hamel, D., Teasdale, N., et al. (2016). Sex-specific association between obesity and self-reported falls and injuries among communitydwelling Canadians aged 65 years and older. Osteoporosis International, 28(2), 483-494.

23. Gama, Z. A. S., \& Gómez-Conesa, A. (2008). Risk factors for falls in the elderly: Systematic review. Revista de Saúde Pública, 42(5), 946-956.

24. Agudelo-Botero, M., Giraldo-Rodríguez, L., Murillo-González, J. C., Mino-León, D., \& Cruz-Arenas, E. (2018). Factors associated with occasional and recurrent falls in Mexican communitydwelling older people. PLoS ONE, 13(2), e0192926.

25. Aged \& Community Services Australia NRHA. (2004). Older people and aged care in rural, regional and remote Australia: A Discussion Paper. Deakin West: ACT: National Rural Health Alliance.

Publisher's Note Springer Nature remains neutral with regard to jurisdictional claims in published maps and institutional affiliations. 